\title{
ORIENTACIÓN UNIVERSITARIA: Marco conceptual de referencia
}

\author{
Luis Carlos Taborda, $M D^{*}$
}

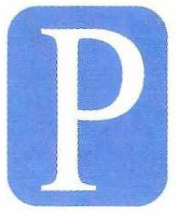

uesto que se trata de la acción permanente de un programa de servicios educativos y formativos para el adecuado desarrollo de las personas de la comunidad universitaria y de su calidad de vida integral, adoptamos como marco de referencia la conceptualización, métodos y estrategias de la Investigación Evaluativa para el mejoramiento continuo de los procesos y la toma de decisiones.

Más que formular metas en términos cuantitativos, en el estilo y la cultura de la investigación evaluativa, se trata de una superación permanente a partir de la misma acción, evaluada con regularidad y con referencia a la misión y la visión de nuestra institución.

El modelo de la Investigación Evaluativa Permanente, debe cumplir con las condiciones señaladas por uno de los padres de esta estrategia y metodología, el profesor Lee Cronbach y acogida en los Estados Unidos por los Standars of Evaluation, los cuales señalan que estos procesos deben cumplir con las siguientes condiciones:

Deben ser:

- Apoyados como política universitaria.

- Oportunos desde el punto de vista conceptual.

- Válidos en su metodología.

- Participativos para la comunidad.

- Legítimos en el contexto ético.

- Útiles para la toma de decisiones.

\section{Plan de Desarrollo}

En concordancia con la conceptualización señalada, la oficina de Orientación Universitaria resume así sus objetivos:

Editorialista invitado. Profesor Titular de Psiquiatría. Director de la Oficina de Orientación Universitaria. Miembro de Número de la Sociedad de Cirugía de Bogotá.
- Dar apoyo calificado a la Dirección de Admisiones para que haya mayor validez en los procesos de selección y seguimiento estudiantil con el fin de contar con los mejores indicadores y predictores.

- Ofrecer servicio de consultoría médico-psiquiátrica o psicológica para la oportuna atención de la orientación primaria de la comunidad universitaria y hacer las remisiones correspondientes con el debido seguimiento.

- Brindar servicios especializados para la prevención y desarrollo de competencias personales y cambios grupales, mediante la organización de talleres, seminarios, grupos de discusión y campañas especiales relacionadas con hábitos de estudio, técnicas de aprendizaje, comunicación y relaciones interpersonales, habilidades para la prevención y resolución de conflictos, prevención de riesgos de adicciones, en el campo del comportamiento sexual, hábitos de salud y mejoramiento de la calidad de vida, problemas de familia, afectivos y estrés, administración del tiempo y el dinero y otros más que la comunidad solicite.

- Diseñar, organizar y mantener actualizadas las bases de datos con fines investigativos y de soporte para la autoevaluación permanente.

- Diseñar, difundiry evaluar metodologías de persuasión, comunicación y educación en el campo de la salud, tendientes al fortalecimiento de factores protectores y al mantenimiento de la salud mental y orgánica.

- Someter los procesos de gestión y la oferta del servicio de Orientación Universitaria a procesos de renovación, actualización y autoevaluación para introducir los ajustes y las mejoras aconsejables.

- Actuar como grupo consultor de las instancias universitarias que lo soliciten. 